\title{
Matching Machine Design to the Production Process: A Case Study in the Integrated Design of Mobile Equipment and Mining Methods
}

\author{
Patrick F.R. Murphy, Sandvik Mining \& Construction Equipment, Burlington, Ontario \\ Laeeque K. Daneshmend, Queen's University, Kingston, Ontario
}

\begin{abstract}
Underground mining imposes very rigid constraints on mobile equipment design. The choice of a particular mining "method" - i.e. the specific mix of techniques for excavation, ground support, and materials handling - is greatly influenced by the nature of the ore body being exploited. Mining methods tend to be fairly conservative, relying upon well established and proven equipment designs. In order to improve worker safety and productivity, South African platinum mines have increasingly turned to mechanization. An added benefit of these mechanization efforts is that the nature of the mining can be modified based on the feasible equipment designs. These efforts have resulted in changes to the mining methods employed in South Africa's narrow-reef platinum group metal (PGM) ore bodies, as well as the development of a suite of mobile equipment which enables implementation of the new production processes. This paper focuses on the design and development of one of these machines - a narrow-reef bulldozer suited to selective mining. The resulting machine is a miniature unmanned bulldozer and multipurpose crawler platform designed for narrow-vein mining applications, with integrated mechatronics and remote control capabilities. This paper will discuss the development of the machine and the applications for which it was designed.
\end{abstract}

